\title{
On the Buddhist Thought in Tang Yin's Poetry
}

\author{
Wu Bo \\ Xianyang Normal University, Xianyang, Shaanxi Province, 712000
}

Keywords: Buddhism; Tang Yin; Carpe diem

\begin{abstract}
Tang Yin's poetry is unique in the Ming Dynasty. Focusing on the text, this paper attempts to analyze the Buddhist thoughts in poetry by combing and exploring Tang Yin's poems. The content mainly includes the following three aspects: the influence of the thought of "life is bitter" on the mentality of Buddhism; the idea of "timelessness, impermanence" and his lifestyle of timely pleasure; the influence of Buddhist thoughts of "indifferent fame and fortune and leisure is a blessing” on his personality and outlook on life.
\end{abstract}

Tang Yin, known as "Liuru Jushi", the name is taken from the "Diamond Sutra": "everything is a law, such as a dream bubble; if the dew is like electricity, should be as if it is a view." He not only often talks with Buddhist monks about Buddhism, but also often explains Buddhism in the form of poetry. After the frustration of his career, he chose to rely on Buddhism to calm his heart, emphasizing timely pleasure and contentment. It can be seen that the illusory and empty thoughts of Buddhism have had a profound influence on him, and these are reflected in his poetry.

\section{The Thought of "Life is Bitter"}

The basic purpose of Buddhism is to purify all beings. The premise is that "everything is bitter." There are two bitternesses, eight bitternesses and even infinite sufferings in life. It is believed that as long as people are born in the world, they will be in the real "suffering" from beginning to end, even if "happiness" is just a form of disguise of "bitterness". Only one heart to the Buddha can escape from the sea of suffering. This kind of life view of Buddhism tells the suffering of the world and has been endorsed by many people. Tang Yin's life was very rough. Because of the imprisonment suffered by the department, he needed to go up and down, and the property of the family had already been spent. The funeral of the family has also been repeated one after another. Coupled with the sluggish market of calligraphy and painting, it is difficult for a family to make a living. Tang Yin sometimes does not even have the clothes to protect himself and he has no food to eat. Suffering from the pain of life, he used to write "Love Vegetables":

"I love green vegetables! I love green vegetables! Do treasure, deceive. It is fine to eat too much. It is helpless to eat less.... I love vegetables, people love meat. Meat does not enter the sages. The bowl of porridge, the three have their own leisure."

The poet advocates the love of vegetable in a fanatical language, but we can learn from the poem "Eat more, eat less and helpless" that the poet's life at that time was very poor. Although he is helpless to life and to his own destiny, he believes that life is bitter, he does not struggle, but is willing to accept the "bitter" life.

Another example is "Man Xing", which is full of frustration and pain in the life of the extension. "Lost and unreasonable, chess is the year of the moon and the wine for the year. Su Qin's cheeks still have tongues, Zhao Yu has no money for the sac. There are so many ridiculous ghosts, and there is no place to worry about the day. Injury, and look at the full moon in the deep cup." (The seventh piece of "Man Xing") The poem truly records the life of the poet in his later years: abandoning the struggle, the intersection of the poor and the sick, and the helplessness. No word is not emotional, no word is not sad. Although life is hard and painful, the poet is still alive, because he knows that life is painful. The idea that "life is bitter" has a profound influence on Tang Yin. When Tang Yin was about to die, he wrote: "There is a field in the sun, and it is no harm to return to the land. The earth and the underground are similar. It is only drifting in a foreign land."("the 
Last Poem") This poem is straightforward. The first two sentences tell people that people have to die after all, what is wrong with going to another world? Perhaps the poet is really suffering and dying for this life, but the best way to escape. Tang Yi's life is bumpy and poor, and if there is no ideological concept of "life is bitter", it is conceivable that he may not be able to sustain it.

\section{The Thought of "Time Flies, Impermanence"}

In order to demonstrate the impermanence of life, the original Buddhism put forward three propositions: " 'the impermanence of the line', the 'the law is without me', the 'everything is bitter', is the 'three laws and seals"”. Buddhism's view is that everything in the world is caused by karma and cohesion. Everything in the world is constantly changing and developing, including all material and human psychological activities. This is the "inevitable law". Everything is lawless. People have life, old age, sickness, and death. Things have life, residence, difference, and destruction. The world has success, living, bad, and empty. The law is impermanent, and the life of a person is made up of many sufferings. This cannot be changed, and thus people have all kinds of pains. This kind of impermanent change is reflected in Tang Yin's poetry. Such as “Citation on Qingjiang”:

"Spring is coming to spring, whiteheads are empty, flowers are blooming, and Zhu Yan is prone to decline; things are floating, and time is like passing passengers... After a hundred years of life, it is super three worlds... How can suffering people escape?”

The poet expresses the sigh of being easy to live, easy to pass, showing Tang Yin's attitude towards life in the world. Tang Yin was jailed for being caught in a fraud in the field. These songs are his works after he was released from prison. The poet re-understands life and expresses goodbye to the past and re-selects the path of life. Tang Yin's thoughts and behaviors are likely to be related to his rough experience. His frustrations made him see the world, and formed his "impermanence" attitude towards life and life in his poetry. This poem is a sigh of impermanence and loss of time. Tang Yin believes that time is as fast as water, and time has passed since unconsciously. Another example is as stated in "The Wine of Flowers under the Flower":

"Ninety springs are on the brink, and before the flower, you can sing high songs. The flowers on the branches can give the day, the life in the world can be geometric. The flowers are difficult to open, and the good years are not easy to return. Life is not drunk before the flowers. Laughing is also a life."

In this poem, Tang Yin expresses the helplessness of life impermanence and time lapse. The first sentence uses exaggerated techniques to express the shortness of life, and then the poem uses the metaphor to write a good time in life. Finally, the poet tells people in anthropomorphic ways that they should always be happy, or even flowers will laugh at them.

In “One Song”, Tang Yin also wrote a sigh of impermanence and timelessness:

"Life is seventy years old, except for the old ones. When there is not much time in the middle, there are frosts and troubles... How many graves in the grass, no one sweeps every year."

This poem describes the impermanence of life and the shortness of time with vivid metaphors and detailed examples. The poet advises us to see the world, not to be troubled by the outside world, to live a life that we have now, to live the true meaning and value of life. Another example is the "Drunk Time Song”: "The water and fire are combined into a false match. The world's dementia recognizes me and causes trouble. I'm so mad at killing and stealing, because I want to be ignorant..." The poem explains the nature of life in Buddhist terms. Buddhist terms such as "madness", "inferiority”, “cultivation”, “all kinds of impermanence”, and "zen” run through the whole poem, explaining the Buddhist thoughts of impermanence and timelessness. In his later years, Tang Yin often talked with the monks about the Buddhist world and used Buddhism to pin their lives. "One inch of time is not temporarily thrown away, and there are hundreds of hardships and sorrows. If you are a long-term customer, you can escape from life.” (One of the "Sighs”) The poet in poetry regards life as nothingness, and poetry writes poet's views on life and wealth on the plain and easy language. It embodies the shortness of life, and should use less cleverness and a natural attitude towards life. The sigh of life is the main idea of these two poems. It is full of the anxiety and embarrassment of the absence of time and the inaction of life, which reflects the influence of 
Buddhist culture on Tang Yin thought. "Occasional” said: "The foreplay of the world lights, life bubbles.” Because Tang Yin was afflicted with humiliation, disappointment, frustration, frustration, hardship, and anger and anger, he whispered 'the two-sleeved gold tears of the future, and the three cases of the public case. The old man should not think about it, and he will continue to go to the leap year of "half awakening and half drunk". The poet treats life and death with the mentality of "no life, no death", thus gaining spiritual relief.

Buddhism fundamentally believes that the real world is illusory, impermanent, and everything is made up of karma. It is an illusion of instant change. Buddhism also believes that "time and space are both birth and death, and they are the origins of the law, not the original ones." The ups and downs of Tang Yin's life made Tang Yin think that life is nothing but illusory. Poems such as "Evening" and "Sighing the World" reflect that Tang Yan has realized the world's feelings and impermanence. In the poem, the poet explains the timeless and ruined Buddhism in Buddhist terms, and believes that no ignorance will result in spiritual relief.

\section{The Thought of "Indifferent to Fame and Fortune, Leisure is a Blessing"}

Buddhism believes that practitioners must see the fame and fortune of the world, and cannot pursue the fame and fortune of the world. What Buddhists have to do is to be innocent, so that they can focus on the spiritual achievements of the Taoism in a clean state of mind. This kind of Buddhist thought is reflected in Tang Yin's poetry. "Looking at the yellow dust road in the middle, the wealth is like me in the cloud" ("Happy Fishing") These two sentences are saying: Looking far away from those who are running for fame and fortune, wealth is like floating in the sky for me. Like a cloud, it is a dream bubble that has plagued people's fame and fortune in history. Why is life so illusory, why bother to pursue something "empty"? Those are meaningless. The poem not only writes the attitude of the fisherman to life, but also writes that the poet prefers to be poor and simple, not to seek wealth. This pinned the poet's indifferent fame and fortune, only seeking a simple and happy attitude towards life. Another example is "Sleeping”, “...remaining sleep has nothing to taste, middle-aged is not in the mood. The world is often provoked by chickens, and it is not a good name.” The last two sentences of the poet: The people in the world are all humming, working hard, and being involuntarily, all for the sake of fame and fortune. On the one hand, the work reflects the lazy leisure of the poet, but on the other hand, it reflects the poet's mentality of seeing the world, and also conveys the indifference of the poet's mood at this time.

Another example is this: "All things are hard to ask, and the children and grandchildren are far away. Drink three glasses of wine and break the chaos, and you can get a sail." It is advisable to solve the problem, and each of them will look back." (the second piece of "Warning") The poet said that all things are arranged in heaven and do not have to go through hard work. After drinking a few glasses of wine, you can't mess around. After a smooth ride, you can collect the sails. Emphasize that life should be accepted when it is in the world. The thought in the poem is in harmony with the sorrow of Buddhism. Buddhism's concept of "bitterness" and "emptiness" made Tang Yan, who suffered many hardships, see through the life and death in life, and fainted the fame and fortune of the world. This thinks that everything in the world will soon disappear, and it is better to be happy in time. So I built my own "Peach Blossoms", recruited friends and gathered friends, letting go of the waves, drinking poems every day, and thinking that leisure is a blessing.

"Peach Blossom Song" is a portrayal of his poverty and loyalty, not seeking wealthy life ethics: “... I hope that the old dead flower and wine, not willing to smash the car before; the car dust is full of fun, the wine cellar is poor If you are richer than the poor, one is in the flat on the ground; if you are poorer than a horse, he has to drive me to idle. Others laugh at me, mad, I laugh and others can't see; I don't see Wuling Heroes' Tomb, No flowers, no wine, no farm.” In the poem, he sketches the image of an extraordinary peach blossom fairy. He indulges in the wine peach blossoms every day, and his life is leisurely. The poet also pointed out that he loved the peach wine because he didn't like to bend for the secular fame and fortune. Finally, the poet warned people that everything in the world will disappear with the passing of time. It is better to let go of these illusory things and seek real. happy. Tang Yin confronted the helplessness in life with the actions of "masturbation" and 
"self-adaptation". This kind of life that is not bound by the outside world is free and free. It is true that the so-called faintness is true. Only grateful and contented life can not worry about the things in front of us, and will cherish the life in front of us. It can be seen that the thought of Buddhism's "tolerance of the world, contentment and happiness" is vividly displayed in Tang Yin's poems.

As a generation of talented scholars, Tang Yan experienced rough and temperament, and Buddhist thoughts made him feel the peace and open-mindedness of the soul after experiencing the pain of disaffiliation and the frustration of his career. It also made his poetry, although the language is vulgar, revealing the world-famous Deep beauty.

\section{Acknowledgements}

Fund Project: special scientific research project of Shaanxi Provincial Department of Education Project Name: The Heterogeneity and Cultural Significance of Tang Yinqi's Poems

Project No.: 17JK0809

\section{References}

[1] (Qing) Kangxi. King Kong Prajna Paramita [M]. China Bookstore Press.

[2] The Tang poems quoted in this article are from Tang Yin. Tang Yin. Tang Bohu’s Complete Works [M]. Beijing China Bookstore, 1985.

[3] Wang Xiaohui. Interpretation of Tang Yin's Life Consciousness [J]. School of Literature, Shandong Normal University, 2003.

[4] Shen Liping. On the Relationship between Tang Yin's Poetry and Wudi Citizen Culture in the Middle of Ming Dynasty[J].Suzhou Industrial Vocational and Technical College,2011(08).

[5] Yuan Chen. Buddhist Thoughts in Tang Yu's Poems [J]. 2007(2).

[6] Selection of Chinese Buddhist History Materials [M]. Beijing: Zhonghua Book Company, 1981. 